\begin{tabular}{|c|c|}
\hline Citation & $\begin{array}{l}\text { Robba C, Giovannini M, (2021), } \\
\text { Intensive Care Admission and Management of Patients With Acute } \\
\text { Ischemic Stroke: A Cross-sectional Survey of the European Society of } \\
\text { Intensive Care Medicine. } \\
\text { Journal of Neurosurgical Anesthesiology, online ahead of print }\end{array}$ \\
\hline Archived version & Final publisher's version / pdf \\
\hline Published version & http://dx.doi.org/10.1097/ANA.0000000000000761 \\
\hline Journal homepage & Journal of Neurosurgical Anesthesiology \\
\hline Author contact & $\begin{array}{l}\text { greet.vandenberghe@kuleuven.be } \\
\text { + } 32(0) 16344021\end{array}$ \\
\hline IR & https://lirias2.kuleuven.be/viewobject.html?cid=1\&id=3396689 \\
\hline
\end{tabular}

(article begins on next page) 
Intensive Care Admission and Management of Patients with Acute Ischemic Stroke: A Cross Sectional Survey of the European Society of Intensive Care Medicine

* The authors have equally contributed to the manuscript

${ }^{a}$ The list of collaborators is at the end of the manuscript

${ }^{1}$ Department of Anaesthesia and Intensive Care, Policlinico San Martino IRCCS for Oncology and Neuroscience, Genoa, Italy.

${ }^{2}$ Department of Surgical Science and Diagnostic Integrated, University of Genoa, Italy

${ }^{3}$ Department of Intensive Care Medicine, University Hospitals Leuven, 3000, Leuven, Belgium

${ }^{4}$ Department of Intensive Care Adults, Erasmus MC - University Medical Center, Rotterdam, the Netherlands

${ }^{5}$ Neurointensive Care Unit, San Gerardo Hospital, ASST-Monza, Monza, MB, Italy

${ }^{6}$ School of Medicine and Surgery, University of Milano - Bicocca, Milano, Italy

${ }^{7}$ Department of Medical Physics and Biomedical Engineering, University College London, London, UK.

${ }^{8}$ Neurocritical Care Unit, The National Hospital for Neurology and Neurosurgery, University College London Hospitals, Queen Square, London, UK

Corresponding author:

Chiara Robba, PhD

Policlinico San Martino, IRCCS for Oncology and Neuroscience, Genova, Italy. Largo Rosanna Benzi 12, 16100.

kiarobba@gmail,com

Tel.003090105551

\section{Fundings: none}

Conflict of interest: MS is the Editor-in-Chief of the Journal of Neurosurgical Anesthesiology; this manuscript was handled by Dr Alana Flexman, Associate Editor. The other authors have no conflict of interest.

Word count: 2917

Tables: 1

Figures:4

Supplementary Digital Contents:12

Results of this survey have been partially presented at the European Society of Intensive Care Meeting LIVESin December 2020. 
Background: No specific recommendations are available regarding the intensive care management of critically ill acute ischemic stroke (AIS) patients, and questions remain regarding optimal ventilatory, hemodynamic and general ICU therapeutic targets in this population. We performed an international survey to investigate intensive care unit (ICU) admission criteria and management of AIS patients.

Methods: An electronic questionnaire including 25 items divided into 3 sections was available on the European Society of Intensive Care Medicine (ESICM) website between $1^{\text {st }}$ November 2019 and $30^{\text {th }}$ March 2020 and advertised through the Neurointensive Care (NIC) section newsletter. This survey was emailed directly to the NIC members and was endorsed by the ESICM.

Results: There were 214 respondents from 198 centers, with response rate of $16,5 \%$ of total membership (214/1296). In most centers (67\%), the number of AIS patients admitted to respondents' hospitals in 2019 was between 100 and 300, and, among them, fewer than 50 required ICU admission per hospital. The most widely accepted indication for ICU admission criteria was a requirement for intubation and mechanical ventilation. A standard protocol for arterial blood pressure (ABP) management was utilized by $88(58 \%)$ of the respondents. For patients eligible for iv thrombolysis, the most common ABP target was $<185 / 110$ $\mathrm{mmHg}(\mathrm{n}=77$ [51\%]), while for patients undergoing mechanical thrombectomy it was $\leq 160 / 90 \mathrm{mmHg}$ ( $n=79[54 \%])$. The preferred drug for reducing ABP was labetalol ( $n=84[55,6 \%])$. Other frequently used therapeutic targets included: blood glucose 140-180 mg/dl ( $\mathrm{n}=65$ [43\%]) maintained with intravenous insulin infusion in most institutions ( $n=110[72,4 \%])$; enteral feeding initiated within $2-3$ days from stroke onset $(n=142[93,4 \%])$; oxygen saturation $\left(\mathrm{SpO}_{2}\right)>95 \%(\mathrm{n}=80[53 \%])$, and tidal volume $6-8 \mathrm{ml} / \mathrm{kg}$ of predicted body weight ( $n=135$ [89\%]).

Conclusions: The ICU management of AIS, including therapeutic targets and clinical practice strategies, importantly varies between centers. Our findings may be helpful to define future studies and create a research agenda regarding the ICU therapeutic targets for AIS patients.

Keywords: acute ischemic stroke; intensive care unit; mechanical ventilation; arterial blood pressure; thrombolysis 


\section{Introduction}

95 Acute ischemic stroke (AIS) is a major cause of mortality and morbidity wordwide. ${ }^{1} \mathrm{~A}$ substantial 96 proportion of patients with AIS require admission to an intensive care unit (ICU) for neurological

97 monitoring and management of general or poststroke complications that cannot be delivered on a stroke 98 unit. $^{2}$

99 The overarching goal of AIS management in both stroke units and ICUs is to target therapeutic efforts to restore blood flow to the penumbra before irreversible tissue injury has occurred in order to minimize secondary brain injury and improve long-term functional outcomes and quality of life. ${ }^{3,4}$ This is accomplished by conceptually optimizing brain perfusion and compensating for associated dysfunction in systemic organ systems. Because of the rapid and irreversible nature of ischemic brain injury, it is crucial for neurocritical care management to begin as early as possible in appropriate patients. ${ }^{2,5,6}$. A number of medical, surgical, and endovascular treatment are associated with improved long-term outcomes. ${ }^{6}$ However, evidence regarding general management of AIS is scarce; therapeutic strategies are often based on specific locally agreed criteria, and questions remains regarding the optimal ventilatory, hemodynamic and general ICU management. ${ }^{2,5-7}$

109 We therefore conducted an international survey: "IndicationS of ICU admission and inTensive caRe management of patlents with acute ischemic stroKE: the STRIKE survey" to assess current criteria for

111 admission to ICU, clinical practice variability, and critical care management of AIS patients. Our hypothesis 112 is that ICU indications and management vary significantly among centers. 


\section{Methods}

The questionnaire underwent a peer-review process within the European Society of Intensive Care Medicine (ESICM) Research Committee. This international survey was endorsed by the ESICM and promoted by the Neuro-intensive Care (NIC) section of ESICM. The survey was registered with the ESICM Survey portfolio, and no ethics approval was required. The questionnaire was distributed by the ESICM office, thus protecting data confidentiality and anonymity using a specific database.

\section{Study population}

The target audience consisted of Neurointensive Care (NIC) section members of the ESICM who had agreed to participate in ESICM surveys at the time of their membership registration, and who manage patients with AIS in their clinical practice. Participants did not receive compensation for their participation in the survey, and response to the survey questionnaire was deemed as implied consent for participation.

\section{Survey development}

The survey was developed by three investigators (C.R., G.C. and M.S.), following a narrative review of the literature on the management of stroke in the ICU. ${ }^{7}$ An electronic questionnaire including 25 items divided into 3 sections was emailed to the NIC members of the ESICM through the section newsletter, and was available on the ESICM website, accessible only by NIC members (1296 members), between $1^{\text {st }}$ November 2019 and $30^{\text {th }}$ March 2020. Multiple responders from each institution were allowed. Two mass reminders were sent during the study period.

The survey questionnaire is shown in the supplementary material (Supplemental digital content (SDC) 1: Survey questionnaire).

The survey participants were asked to score (on a scale of 0 to 10 according to the priority of their management) responses to different factors aimed to guide specific clinical decisions during AIS patients' management (e.g. ICU admission criteria, neuromonitoring choices, indication for tracheostomy). Singleanswer questions were asked about specific area of management, including glycemic control, ventilation, temperature, arterial blood pressure, thrombotic risk, management of dysphagia and speech disturbance. The questions allowed only one single answer, and multiple answers were accepted only for the following questions: Section 2, question 4; Section 3, question 1, 16,17 (SDC 1: Survey questionnaire).

The survey was designed to identify (within 3 sections):

Section 1: Survey participants' demographics, type of hospital/ICU, catchment area population for AIS, number of ICU beds, medical and nurse staffing, and the presence of neurointerventional service or stroke unit. 
149 Section 2: General information and criteria for ICU admission of AIS patients in the respondents' 150 institution.

151 Section 3: Specific aspects of the ICU management of AIS patients in the respondents' institution.

152

153

154

155 156

15 158 159 160 161
Statistical analysis

Variables are reported as percentages of the total responses; if a "none" response was allowed in the questionnaire, percentage was calculated using only reported values. Numerical variables are presented as median and interquartile range (IQR), as they were not normally distributed. Results are presented according to micro-macro geographical areas to test our hypothesis. Descriptive analysis was performed using statistical package of " $R$ " software ver. 4.0.2. Level of significance was considered as $p<0.05$. 
There were 214 responses from 198 centers and 54 countries around the world, with a response rate of $214 / 1296(16,5 \%)$ of total registered members of the NIC section. A significant proportion of the respondents ( $n=73,3 \%$ ) did not provide complete information, and only partial responses were included in the analysis.

More than one half of the respondents were from European countries ( $n=130$ [61\%]); Spain was the country with the highest number of respondents $(n=18)$, followed by India $(n=16)$, United Kingdom $(n=15)$, Italy ( $n=14)$ and France ( $n=12)$ (SDC 2, Supplementary Table S1: Countries of respondents). The majority of respondents were general intensivists ( $n=126$ [59\%]), and 27\% $(n=57)$ worked in dedicated neuro-intensive care units. Baseline characteristics of the respondents are summarized in the supplementary material (Table1, and SDC 3, Supplementary figure S1: Geographic areas of respondents). Large variability was observed between centers and countries.

The number of patients with AIS admitted to the hospital in 2019 was between 100 and 300 according to the majority of the responders ( $n=90 ; 67 \%$ ); among these, fewer than 50 required ICU admission in most cases $(n=64,35,5 \%)$. In half of the centers $(n=82 ; 51,2 \%)$ less than $20 \%$ of AIS patients underwent intravenous thrombolysis in 2019, while fewer than $10 \%(n=68 ; 49,3 \%)$ of AIS patient were eligible for mechanical thrombectomy, with large variability among countries (SDC 4, Supplementary Figure S2: Percentage of patients undergoing thrombolysis and mechanical thrombectomy).

The most widely accepted ICU admission criteria were need for intubation and mechanical ventilation (median score on scale 0-10: 10, IQR 9-10), need for systemic organ support (10, IQR 9-10) and management of intracranial complications (10, IQR9-10) (Figure 1). Table 2, and SDC 5 (Supplementary Table S3: General ICU management) summarize the details of key ICU targets and management principles.

A standard protocol for ABP management was utilized by 88 (58\%) of respondents. For patients eligible for iv thrombolysis, the most common ABP target was $\leq 185 / 110 \mathrm{mmHg}(\mathrm{n}=77$ [51\%]), the same as for those ineligible for this procedure $(n=64[43 \%])$. For patients undergoing mechanical thrombectomy, the most common $A B P$ target was $\leq 160 / 90 \mathrm{mmHg}(\mathrm{n}=79[54 \%])$. The preferred drugs for reducing $A B P$ were continuous intravenous administration of labetalol $(n=84[55,6 \%])$ and nicardipine $(n=25[16,6 \%])($ Table 2).

Blood glucose levels were most frequently monitored every 4 hours ( $n=61[40 \%]$ ), and the most frequently used glycemic target was 140-180 mg/dl ( $\mathrm{n=65}$ [43\%]) (Figure 2). Glycemic control was achieved by intravenous insulin infusion in most institutions ( $n=110[72,4 \%])$. Enteral feeding was started between days 
of enteral feeding). With regard to respiratory management, the most common oxygen saturation $\left(\mathrm{SpO}_{2}\right)$ target was $>95 \%(n=80[53 \%])$, the most common end tidal carbon dioxide $\left(\mathrm{EtCO}_{2}\right)$ target was $35-40 \mathrm{mmHg}$ $(\mathrm{n}=89[59 \%])$, and the most commonly used tidal volume in mechanically ventilated patients was 6-8 $\mathrm{ml} / \mathrm{kg}$ of predicted body weight $(n=135$ [89\%])(SDC 7, Supplementary Figure S4: Ventilator targets and management). A target temperature $\leq 37,5^{\circ} \mathrm{C}(\mathrm{n}=99[65 \%])$ was preferred in most centers, and the most used treatment for fever was antipyretic drugs ( $n=129$ [85\%]).

Thromboembolic prophylaxis was most frequently initiated within 2 days from stroke onset $(n=121$ $[79,6 \%])$; most respondents ( $n=89[58,6 \%]$ ) used intermitted pneumatic devices as the preferred physical method for prophylaxis (SDC 8, Supplementary Figure S5: Thromboprophylaxis). The most common hemoglobin trigger for transfusion was $7-8 \mathrm{mg} / \mathrm{dl}(\mathrm{n}=107 \quad[70,4 \%])($ SDC 9, Figure S6: Transfusion thresholds).

According to most of the respondents ( $n=126$ [78\%]), fewer than $10 \%$ of AIS patients underwent decompressive craniectomy in 2019 (SDC 10 - Figure S7: Decompressive craniectomy rates).

Clinical observation was considered the most important "neuromonitoring" technique for AIS patients in the ICU (median score 10, IQR 10-10), followed by intermitted electroencephalography (EEG) (median score 5, IQR 3-10) and transcranial Doppler ultrasound (5, IQR1-8) (SDC 11, Figure S8: Neuromonitoring).

Access to speech and language therapists was reported by 82 (54\%) respondents; stroke-related dysphagia was mostly assessed clinically (102 [67\%]), with a bolus of food (Figure 3). The main indications for tracheostomy in AIS patients in the ICU were poor neurological status (median score 9, IQR 8-10), followed by repeated extubation failures (9, IQR 7-10). Tracheostomy was typically performed after 8 days from the event in most institutions ( $\mathrm{n}=91$ [60\%])(SDC 12, Figure S9: Timing and indication for tracheostomy). 


\section{Discussion}

This international survey provides information regarding ICU admission criteria and ICU management of patients with AIS. Our results provide an overview of current clinical practices and their variation across several countries and stroke centers, thus representing the current state of affairs regarding the ICU management of AIS patients, which may be influenced by location (country), local, regional and national guidelines. Although variability between centers might potentially lead to innovation, the development of specific and universal guidelines may assist clinicians in their practice.

This survey reports a high variability among respondents with regard to type of ICU, hospital and number of general vs neuro ICU beds, type of medical staff and management of AIS patients, with consequent different availability of resources, standardization of care at institutional care, performance measures, public reporting of data etc.

\section{Indications for ICU admission}

The indications for ICU admission of patients with AIS are variable; this likely depends on several factors, including the level of care that can be provided in the institution's stroke unit, availability of intermediate care units (such as step-up of step-down from ICU) and local preferences. ${ }^{7-10}$

The availability of more aggressive treatments and interventional approaches has led to an increasing number of AIS patients being admitted to the ICU. ${ }^{11}$ The literature suggests that common indications for ICU admission include the need for intubation and/or mechanical ventilation due to respiratory failure and/or decreased level of consciousness with loss of airway protection, blood pressure management, systemic organ system support (e.g. for cardiac failure, acute kidney injury) management of cerebral complications (seizures, post-intervention or anticoagulation hemorrhage, malignant infarction or post decompressive craniectomy). 7,12-15 The results of our survey are in line with these previous reports, with the most common indication for ICU admission being a need for airway management or systemic organ support or monitoring and management of intracranial complications that cannot be managed in the stroke units. ICU admission indications are likely related on the level of care provided by stroke units, and number of specialized neurocritical care units; in fact, in some countries, staffing and care of patients in a stroke unit be a satisfactory replacement to the ICU.

As presented in Table 1, the total number of dedicated neurocritical care units according to our responders is low, and the ICUs are small to moderate size. This suggests that ICU admission criteria are stricter and use ICU resource only for the sickest patients, and not for monitoring or routinely after mechanical thrombectomy. 


\section{Neuromonitoring}

Limited data are available regarding the role of neuromonitoring after AIS. Most patients are not sedated, thus making clinical assessment the most useful monitoring tool in this cohort.

Transcranial Doppler (TCD) ultrasonography is a safe, bedside tool able for the assessment of cerebral blood flow and potentially useful in the detection of acute vessels occlusion and to assess cerebral and vasoreactivity ${ }^{16,17}$ TCD and near-infrared spectroscopy allow assessment of autoregulatory indexes that have been reported to identify individualized optimal ABP/ cerebral perfusion pressure targets. ${ }^{18}$ EEG can be useful to detect subclinical seizures which may occur after AIS. ${ }^{19}$ Routine ICP monitoring is not recommended after AIS but can be considered in patients with large infarct areas or hemorrhagic complications and significant midline shift. ${ }^{20}$ Finally, evidence on the utility of brain tissue oxygen tension (PtiO2) and pupillometry are lacking and are currently not routinely used.

As no neuromonitoring technique can be considered the gold standard, and has limitations, a multimodal approach- according to availability of resources, standardization of care at institutional care- is warranted.

\section{Ventilation}

Patients with AIS often require intubation and mechanical ventilation because of airway or respiratory compromise or pharyngeal dysfunction, 6,21-25 Hypoxemia should be avoided to minimize secondary brain damage, ${ }^{26}$ but a randomized controlled trial found no benefit on 90-days functional outcome of oxygen administration with $\mathrm{SpO} 2>93 \%$ versus $\leq 93 \% ;{ }^{27}$ the most recent guidelines suggest maintenance of SpO2 $>94 \%$ and avoidance of supplemental oxygen in non-hypoxemic patients ${ }^{6}$. No specific recommendations are available regarding $\mathrm{PaCO} 2$ targets and ventilator management, but the use of protective ventilation strategies, including low tidal volume (while maintaining normocapnia) and positive end expiratory pressure titrated to optimize systemic oxygenation while avoiding hemodynamic instability and alveolar overdistension have been suggested..$^{21}$

Similarly, the indications for performing a tracheostomy in AIS patients include both respiratory (more than one extubation failure) and neurological (impaired brainstem reflexes or level of consciousness) factors. No specific guidelines are available regarding the optimal time for performing a tracheostomy after AIS, but recent evidence in traumatic brain injured patients suggest that early tracheostomy might be associated with reduced ICU length of stay. ${ }^{28,29}$ In contrast, the results from our survey suggest that late tracheostomy (>8 days) is favored, although with large variability among centers, possibly because of the potential risk of intracranial instability in the early phases. This suggests that the decision to perform a tracheostomy is mostly driven by local policies and resources. 


\section{Blood pressure}

Patients with AIS often present with systemic hypertension. Strict management of ABP is mandatory in order to reduce the risks of hypertension (hemorrhagic complications, cerebral edema, cardiovascular complications), while avoiding hypoperfusion and the risk of inadequate blood flow to the ischemic penumbra. ${ }^{7,30,31}$ Hypertension is also associated with several complications after endovascular treatment. ${ }^{32}$ Guidelines recommend that patients with elevated blood pressure who are eligible for endovascular treatment with alteplase should have ABP reduced $<185 / 110 \mathrm{~mm} \mathrm{Hg}$ before intravenous (iv) fibrinolytic therapy is initiated. ${ }^{6}$ There is no clear evidence to guide ABP targets in the post procedural phase or in cases of mechanical thrombectomy, but most of the responders suggested an ABP target of 160/90. In the absence of specific recommendations, according to our responder, labetalol is the first drug of choice for blood pressure control, followed by nicardipine.

\section{Glucose/insulin/nutrition}

Strict monitoring of blood glucose is mandatory in AIS patients, as both hypo and hyperglycemia are associated with adverse outcomes, particularly in relation to the potential effect of glycemic derangements and cerebral blood flow. ${ }^{33}$ A blood glucose concentration of $140-180 \mathrm{mg} / \mathrm{dL}$ is the most used target worldwide, as recommended by the latest guidelines. ${ }^{6}$ However, optimal glycemic management after AIS remain controversial. The recent Stroke Hyperglycemia Insulin Network Effort (SHINE) study ${ }^{34}$ demonstrated that intensive glucose control $(80-130 \mathrm{mg} / \mathrm{dL})$ with insulin infusion has no beneficial effect on 90-day functional outcomes when compared with standard control $(<180 \mathrm{mg} / \mathrm{dL}$ ) with intermittent subcutaneous insulin. As consequence, different strategies for glucose control are being used worldwide (including continuous glucose monitors), with large variability among centers and countries. Regardless of the strategy used, frequent checks of glucose values (every 4 hours) to reduce the risk of hypoglycemia are warranted. Enteral feeding started within 7 days from admission has a favorable effect on outcome, with a reduction of $5.8 \%$ in mortality after AIS. ${ }^{35}$ Specifically, most clinicians prefer very early initiation of enteral feeding (within 2-3 days), with the early insertion of a nasogastric tube in case of dysphagia.

\section{Temperature control}

Fever is common after AIS, with temperature $>37.5^{\circ} \mathrm{C}$ occurring in up to $25 \%$ of patients in the first 6 hours after stroke onset and in about $30 \%$ in the first $24 h .^{2,7}$ Fever may have an infective or neurogenic origin, and is associated with poor outcome. ${ }^{36}$ However, whether targeted temperature management (TTM) policies improve outcome has not been investigated. Further, no clear evidence is available 
regarding the threshold of temperature for TTM after AIS; a recent consensus in brain injured patients suggested starting TTM when temperature is $>37.5$ degrees, which is consistent with the results from our survey. ${ }^{37}$ Antipyretic drugs are first-line therapy for fever after AIS, although treatment with paracetamol seems not to be effective. ${ }^{38}$ Secondary interventions include external and intravascular cooling methods. Type and timing of temperature management are strongly influenced by local policies and resources.

\section{Other issues}

According to our survey, a hemoglobin concentration of $7-8 \mathrm{mg} / \mathrm{dL}$ is generally accepted as the trigger for red cell transfusion of to optimize cerebral oxygen delivery and minimizing the adverse effects of transfusion.

Venous thromboembolism (VTE) is very common after AIS (10-75\%) and is potentially a life-threatening complication. ${ }^{39}$ VTE prophylaxis should always be considered when and initiated when the potential benefits outweigh bleeding risks. ${ }^{6}$ The use of intermittent pneumatic compression in stroke patients without contraindications is strongly recommended. The Clots in Legs Or sTockings after Stroke (CLOTS)3 trial found that, compared to routine care, intermittent pneumatic compression can significantly reduce the incidence of deep-vein thrombosis and improve outcomes. ${ }^{40}$ Our survey revealed that low molecular weight heparin is generally started within 1-2 days from stroke, and intermittent pneumatic compression is the preferred option for deep venous thrombosis prophylaxis.

Finally, dysphagia occurs in $23-50 \%$ of AIS patients and increases the risks of aspiration pneumonia, affecting morbidity and mortality. ${ }^{7}$ Recent guidelines suggest an early nurse-led swallow assessment followed by fibreoptic evaluation in those at risk for aspiration. ${ }^{6}$ In our survey, we found that clinical evaluation is the preferred method for dysphagia assessment, with very low use of fiberoscopy, vidoefluoroscopy or clinical scores, but also with large variability between centers.

\section{Limitations}

There are several limitations to this study. First, the number of respondents is relatively small, making it difficult to generalize the findings of the study. The low response rate may be due to the fact that the survey was started just before the first peak of the first Covid-19. However, the response rate is similar to a previously published survey from the ESICM. ${ }^{41}$ Unfortunately, the response rate cannot be precisely calculated as NIC-ESICM members were invited to forward the invitation to relevant colleagues, thus making it impossible to obtain the total number of people who received the survey. Second, this survey was developed after conducting a narrative review of the literature rather than a systematic review. Third, this survey was not previously validated, and the impact of the results is therefore reduced; pilot testing of the questionnaire was not conducted in a smaller sample of participants prior to the survey. Furthermore, important information is missing, including the presence of triage mechanisms or institutional ICU 
admissions policies among countries, details regarding the type treatment and location of ischemic strokes, data on hemorrhagic transformation, and post stroke vascular reserve or collateralization. Moreover, the processes and clinical practices that identified by this survey are those before the start of the COVID-19 pandemic and some treatment pathways and management policies may be different now. Finally, this survey only describes the perception of the clinical practice according to the respondents, without inclusion of patient data, and more than one responder per center was allowed to answer, thus making the results less generalizable.

\section{Conclusions}

This international survey identified important institutional differences in the ICU management of AIS patients, and many questions about optimal management remain. The survey highlights specific areas with large practice variability among centers, and those areas with clinical equipoise with regard to the management of critically ill AIS patients. Individualized arterial blood pressure management, protective ventilation strategies and hemoglobin targets are areas that have been increasingly developed over the last years. The findings of this survey might be useful to inform the design of future randomized clinical studies and comparative effectiveness research, as well as more specific recommendations/guidelines on this topic.

Acknowledgments: The authors would like to thank Mrs Sherihane Bensemmane and ESICM for the support in the development of the study.

\section{References}

1. Gorelick PB. The global burden of stroke: persistent and disabling. Lancet Neurol 2019: 18:417-418 .

2. Kirkman MA, Citerio G, Smith $M$ The intensive care management of acute ischemic stroke: an overview. Intensive Care Med. 2014; 40:640-653

3. Bandera $\mathrm{E}$, Botteri $\mathrm{M}$, Minelli $\mathrm{C}$ et al. Cerebral blood flow threshold of ischemic penumbra and infarct core in acute ischemic stroke: a systematic review. Stroke 2006: 37:1334-1339

4. Klug J, Dirren E, Preti MG et al.Integrating regional perfusion CT information to improve prediction of infarction after stroke. J Cereb Blood Flow Metab. 2020 Jun 5:271678X20924549. 
5. Stroke Unit Trialists' Collaboration. Organised inpatient (stroke unit) care for stroke. Cochrane Database Syst Rev 2013: 9:CD000197.

6. Powers WJ, Rabinstein AA, Ackerson T, et al. Guidelines for the early management of patients with acute ischemic stroke: a guideline for healthcare professionals from the American Heart Association/American Stroke Association. Stroke .2018; 49:e46-e110

7. Smith $M$, Reddy U, Robba C, Sharma D et al.Acute ischemic stroke: challenges for the intensivist. Intensive Care Med 2019 Sep; 45(9): 1177-1189.

8. Campbell BCV, Khatri P. Stroke.Lancet. 2020 Jul 11;396(10244):129-142.

9. Campbell BCV, De Silva DA, Macleod MR, et al. Ischaemic stroke.Nat Rev Dis Primers. 2019 Oct 10;5(1):70.

10. Campbell BC. Advances in stroke medicine.Med J Aust. 2019 May;210(8):367-374.

11. Zazulia AR Critical care management of acute ischemic stroke. Continuum (Minneap Minn) 2009: 15:68-82

12.Jadhav AP, Molyneaux BJ, Hill MD,et al .Care of the postthrombectomy patient. Stroke.2018: 49:2801-2807

13. Kasner SE. Clinical interpretation and use of stroke scales. Lancet Neurol 2006: 5:603-612

14. Knopf L, Staff I, Gomes J, McCullough L (2012) Impact of a neurointensivist on outcomes in critically ill stroke patients. Neurocrit Care 16:63-71

15. Pelosi P, Ferguson ND, Frutos-Vivar F et al. Management and outcome of mechanically ventilated neurologic patients. Crit Care Med 2011: 39:1482-1492

16. Robba C, Goffi A, Geeraerts T et al. Brain ultrasonography: methodology, basic and advanced principles and clinical applications. A narrative review. Intensive Care Med 2019 Jul;45(7):913-927.

17. Robba C, Cardim D, Sekhon M et al. Trancranial Doppler, a sthetoscope for the brain. J Neurosci Res. 2018 Apr;96(4):720730

18. Petersen NH., Silverman A, Strander SM et al. Fixed Compared With Autoregulation-Oriented Blood Pressure Thresholds After Mechanical Thrombectomy for Ischemic Stroke. Stroke. 2020 Mar; 51(3): 914-921

19. Kawano T, Hattori N, Uno Y, et al. Electroencephalographic Phase Synchrony Index as a Biomarker of Poststroke Motor Impairment and Recovery.Neurorehabil Neural Repair. 2020 Jul 21:1545968320935820.

20. Korbakis G, Vespa PM.Multimodal neurologic monitoring. Handb Clin Neurol. 2017;140:91-105.

21. Robba C, Bonatti G, Battaglini D et al. Mechanical ventilation in acute ischemic stroke: from pathophysiology to clinical practice. Crit Care 2019 Dec 2;23(1):388.

22. Samary CS, Ramos AB, Maia LA, et al. Focal ischemic stroke leads to lung injury and reduces alveolar macrophage phagocytic capability in rats. Crit Care. 2018;22:249

23. Kiphuth IC, Schellinger PD, Kohrmann M et al. Predictors for good functional outcome after neurocritical care. Crit Care 2010: 14:R136

24. Santoli F, De JB, Hayon J et al. Mechanical ventilation in patients with acute ischemic stroke: survival and outcome at one year. Intensive Care Med 2001; 27:1141-1146

25. Berrouschot J, Rossler A, Koster J et al. Mechanical ventilation in patients with hemispheric ischemic stroke. Crit Care Med 2000 28:2956-2961

26. Rowat AM, Dennis MS, Wardlaw JM. Hypoxaemia in acute stroke is frequent and worsens outcome. Cerebrovasc Dis 2006; 21:166-172

27. Roffe C, Nevatte T, Sim J, et al. Stroke Oxygen Study Investigators and the Stroke Oxygen Study Collaborative Group. 
Effect of routine low-dose oxygen supplementation on death and disability in adults with acute stroke: the Stroke Oxygen Study Randomized Clinical Trial. JAMA. 2017;318:1125-1135.

28. Robba C, Galimberti S, Graziano F et al. Tracheostomy practice and timing in traumatic brain-injured patients: a CENTERTBI study. Intensive Care Med 2020 May;46(5):983-994.

29. Mc Credie VA, Alali AS, Scales DC et al. Effect of Early Versus Late Tracheostomy or Prolonged Intubation in Critically III Patients with Acute Brain Injury: A Systematic Review and Meta-Analysis.Neurocrit Care. 2017 Feb;26(1):14-25.

30. Astrup J, Siesjo BK, Symon L. Thresholds in cerebral ischemia-the ischemic penumbra. Stroke 1981: 12:723-725

31. Lo EH. A new penumbra: transitioning from injury into repair after stroke. Nat Med 2008: 14:497-500

32. Mistry EA, Mistry AM, Nakawah MO, et al. Systolic blood pressure within 24 hours after thrombectomy for acute ischemic stroke correlates with outcome. J Am Heart Assoc 2017. 6:e006167.

33.Cryer PE. Hypoglycemia, functional brain failure, and brain death. J Clin Investig 2007: 117:868-870. Kagansky N, Levy S, Knobler H (2001) The role of hyperglycemia in acute stroke. Arch Neurol 58:1209-1212

34.Johnston KC, Bruno A, Barrett K, et al. Stroke hyperglycemia insulin network effort (SHINE) trial primary results. International Stroke Conference 1189 2019. Available at: https ://nett.umich .edu/sites /defau lt/files /docs/shine isc_2019.final .pdf. Accessed 16 Apr 2019

35. Dennis M, Lewis S, Cranswick G, Forbes J; FOOD Trial Collaboration. FOOD: a multicentre randomised trial evaluating feeding policies in patients admitted to hospital with a recent stroke. Health Technol Assess. 2006;10:iii-iv, ix.

36.Greer DM, Funk SE, Reaven NL et al. Impact

of fever on outcome in patients with stroke and neurologic injury: a comprehensive meta-analysis. Stroke 2008: 39:30293035

37.Andrews PJD, Verma V, Healy $\mathrm{M}$ et al. Targeted temperature management in patients with intracerebral haemorrhage, subarachnoid haemorrhage, or acute ischaemic stroke: consensus recommendations. Br J Anaesth 2018: 121:768-775

38.den Hertog HM, van der Worp HB, van Gemert HM et al. The paracetamol (acetaminophen) in stroke (PAIS) trial: a multicentre, randomised, placebo-controlled, phase III trial. Lancet Neurol 2008: 8:434-440

39.Bembenek J, Karlinski M, Kobayashi A, et al. Early strokerelated deep venous thrombosis: risk factors and influence on outcome. J Thromb Thrombolysis 2011: 32:96-102

40. Dennis M, Sandercock P, Reid J, et al. Effectiveness of intermittent pneumatic compression in reduction of risk of deep vein thrombosis in patients who have had a stroke (CLOTS 3): a multicentre randomised controlled trial. Lancet 2013: 382:516-524

41.Picetti E, Pelosi P, Taccone F et al. VENTILatOry strategies in patients with severe traumatic brain injury: the VENTILO Survey of the European Society of Intensive Care Medicine (ESICM). Crit Care. 2020 Apr 17;24(1):158. 


\section{Figures}

\section{Figure 1}

Indications for ICU admission

Values are presented as median value and interquartile range. Circles represent outlier values.

Stroke severity; according to clinical and radiological characteristics; phys, physiological

$A B P$, arterial blood pressure; ICU, intensive care unit; $M C A$, middle cerebral artery

\section{Figure 2}

Glucose targets in acute stroke patients the intensive care unit

\section{Figure 3}

Methods to assess dysphagia in the ICU in acute ischemic stroke patients

$I C U$, intensive care unit 
Supplemental digital content 1

Survey Questionnaire

SDC 1.pdf

Supplemental digital content 2

Table S1: Countries of respondents

SDC 2. pdf

Supplemental digital content 3

Figure S1: Geographic areas of the responders

SDC 3. pdf

Supplemental digital content 4

Figure S2: Thrombolysis and mechanical thrombectomy. The zero level corresponds to the threshold of " $10 \%$ " of patients undergoing mechanical thrombectomy. The values below 0 both include the ' $<10 \%$ ' and 'unknown' responses, to differentiate small hospitals from first level referral hospitals.

SDC 4. pdf

Supplemental digital content 5

Table S3: General ICU Management

SDC 5. pdf

Supplemental digital content 6

Figure S3: Insulin use and timing for start of enteral feeding SDC 6. pdf

Supplemental digital content 7

Figure S4: Ventilator targets and management

SDC 7. pdf

Supplemental digital content 8

Figure S5: Thromboembolic prophylaxis

SDC 8. pdf 
Supplemental digital content 9

Figure S6: Hemoglobin threshold for transfusions

SDC 9. pdf

Supplemental digital content 10

Figure S7: Decompressive craniectomy in acute ischemic stroke

SDC 10. pdf

Supplemental digital content 11

Figure S8: Type of neuromonitoring. Values are presented as median value and interquartile range.

Circles represent outlier values.

SDC 11. pdf

Supplemental digital content 12

Figure S9: Indications and timing for tracheostomy

SDC 12. pdf 



\section{List of collaborators}

\begin{tabular}{|c|c|c|c|}
\hline Name & Affiliation & City/Town & State/Province \\
\hline Juan Luis Pinedo Portilla & Hospital Nacional Almanzor Aguinaga Asenjo & Chiclayo & Chiclayo \\
\hline Iole Brunetti & \multicolumn{3}{|l|}{ Policlinico San Martino, IRCCS for Oncology and Neuroscience, Genova, Italy } \\
\hline MOULRONT S. & CH Dunkerque & DUNKERQUE & NORD \\
\hline Tomasz Torlinski & QEHB UHB NHS FT & Birmingham & West Midlands \\
\hline Bruno Maia & Centro Hospitalar Universitário de Lisboa Central & Lisboa & \\
\hline Raimund Helbok & Medical University of Innsbruck & Innsbruck & Tirol \\
\hline DIEGO MOROCHO TUTILLO & HOSPITAL DE ESPECIALIDADES EUGENIO ESPEJO & QUITO & PICHINCHA \\
\hline Georgios Papathanakos & Assistant Professor of Intensive Care Medicine & loannina & Ipiros \\
\hline Marco Carbonara & Fondazione IRCCS Ca' Granda Ospedale Maggiore Policlinico & Milano & Milano \\
\hline Ron Neyens & Medical University of South Carolina & Charleston & SC \\
\hline Sofia Dias & UCI Neurocríticos e Trauma, Hospital São José & Lisboa & Lisboa \\
\hline Killen Harold Briones Claudett & Universidad de guayaquil. Facultad de Ciencias Médicas & Guayaquil & Guaayas \\
\hline Thomas Rechnitzer & Royal Melbourne Hospital & Parkville & Victoria \\
\hline Dr Paul Wong & Farrer Park Hospital & Singapore & Singapore \\
\hline abdelwadod & abuturki & hebron & palestine \\
\hline Victoria McCredie & University of Toronto & Toronto & Ontario \\
\hline Seri Sunarmiasih & Army central hospital & Jakarta & DKI \\
\hline Alex Harrison & Brighton and Sussex University Hospitals NHS Trust & Brighton & GB \\
\hline Dr Christopher Beck & AGAPLESION & Bad Pyrmont & Lower Saxony \\
\hline Ruby Parveen & Houston Methodist Baytown & & \\
\hline Sonneville Romain & APHP, Bichat university hospital & Houston & Texas \\
\hline Krishna mylavarapu & Baptist & Paris & Ile de France \\
\hline Ricard Mellado Artigas & Surgical ICU. Department of Anesthesia. Hospital Clinic & Little Rock & Arkansas \\
\hline Patrick Schramm & University Medical Centre Main & Barcelona & Catalunya \\
\hline Ahmad Fayed & Qasr Al-Ainy School of Medicine & Mainz & Rheinland-Pfalz \\
\hline Rob Wilting & ETZ & Cairo & Al-Manial \\
\hline Anna Hall & Zorgsaam & Tilburg & Noord-Brabant \\
\hline DIMITRIOS PAPADOPOULOS & General Hospital of Larisa ICU & Terneuzen & Zeeland \\
\hline Veronika Reinhard & Tartu University Hospital & Larisa & Larisa \\
\hline H.Hartziekenhuis & Idem & Tartu & Tartumaa \\
\hline Ricard Mellado Artigas & Surgical ICU. Department of Anesthesia. Hospital Clinic & Lier & Antwerp \\
\hline Patricio Maskin & FLENI & Barcelona & Catalunya \\
\hline Vitalii Saskin & Aleksandrovich & Buenos Aires & Buenos Aires \\
\hline Emanuela Keller & $\begin{array}{l}\text { Neurocritical Care Unit } \\
\text { Anesthesia and intensive care, Policlinico San Martino Hospital, IRCCS }\end{array}$ & Arkhangelsk & Arhangelsk region \\
\hline Matilde Bastianello & for Oncology and Neuroscience & Zurich & Zurich \\
\hline Alessandro Prior & Department of Neurosurgery, Policlinico San Martino, Genova, Italy & Genova & GE \\
\hline Mohammad Ashraf Drabu & Dr Sulaiman al habib hospital riyadh & & \\
\hline Ezequiel Manrique & HOSPITAL PRIVADO UNIVERSITARIO DE CORDOBA & Riyadh & Riyadh \\
\hline Sanchita Garg & Fortis hospital Mohali & Cordoba & Cordoba \\
\hline Moos Matthias & Kantonsspital Frauenfeld & Mohali & Punjab \\
\hline Sergio Canestrini & King's College Hospital NHS Foundation Trust & Frauenfeld & Kanton Thurgau \\
\hline Jouko Kähkönen & Central Hospital & London & Greater London \\
\hline Casiano Barrera Groba & BSUH & Seinäjoki & Western-Finland \\
\hline Antigoni Karathanou & $\begin{array}{l}\text { G.H.Volos Achillopouleio } \\
\text { Policlinico San Martino, IRCCS for Oncology and Neuroscience, }\end{array}$ & Brighton & $\mathrm{E}$ \\
\hline Paolo Frisoni & Genova, Italy & Volos & Magnesia \\
\hline Yuti Sheth & Doctor & & \\
\hline Pasquale Anania & Department of Neurosurgery, Policlinico San Martino, Genova, Italy & Mumbai & Vile Parle(w) \\
\hline Dr Nissar Shaikh & Hamad medical corporation & & \\
\hline Alexey Gritsan & Professor & Doha & Qatar \\
\hline Sasa Dragic & University Clinical Centre of Republic of Srpska & Krasnoyarsk & Krasnoyarsk Regior \\
\hline Mariona Badia & Hospital Arnau de Vilanova & Banja Luka & Republic of Srpska \\
\hline
\end{tabular}




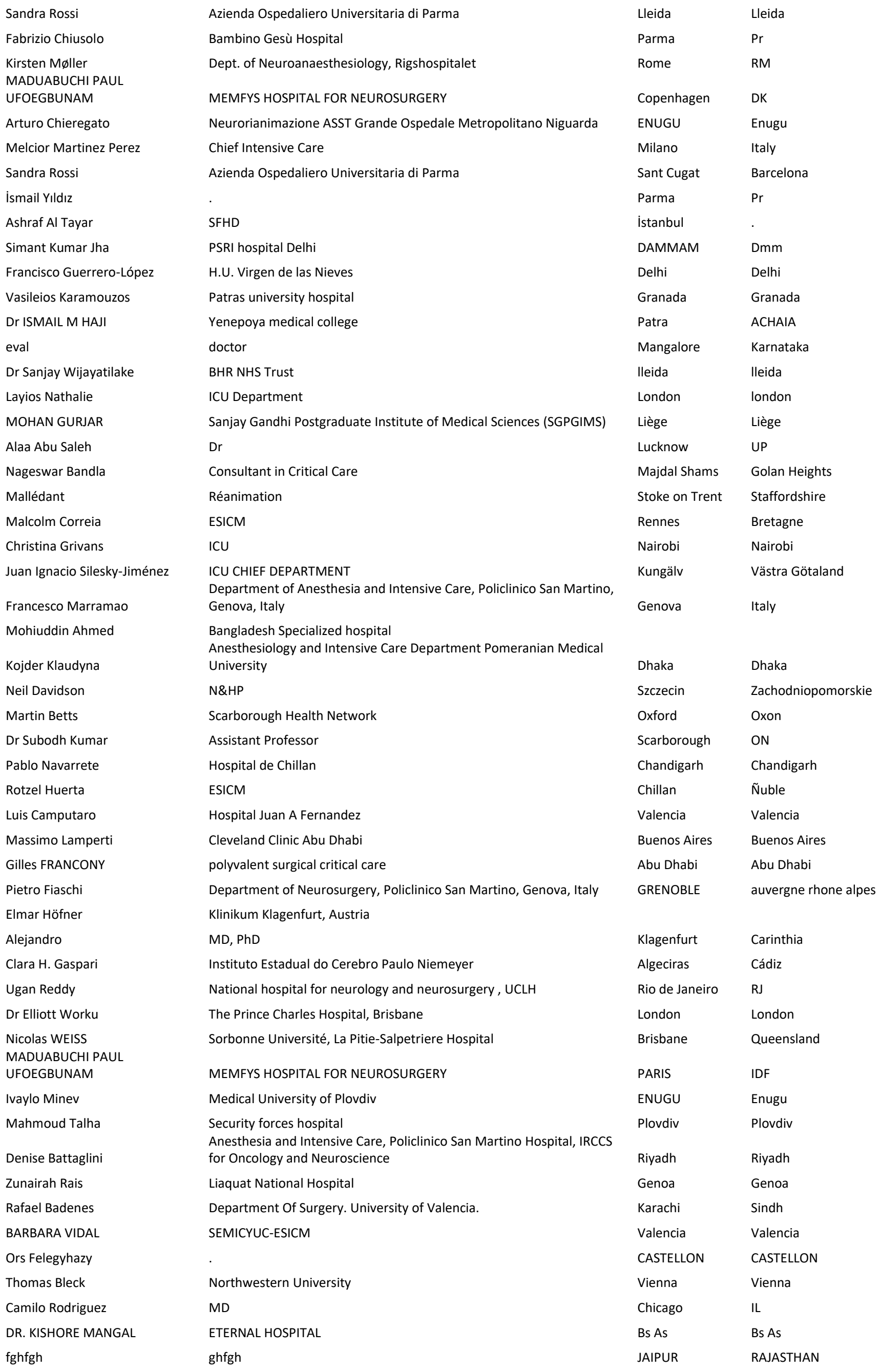




\begin{tabular}{|c|c|c|c|}
\hline FOTEINI CHATZIVASILOGLOU & ICU, Tzaneio General Hospital of Piraeus & gfhfgh & fhfgh \\
\hline Vasiliki Chantziara & SAINT SAVVAS HOSPITAL & PIRAEUS & ATTIKI \\
\hline Thomas Rechnitzer & Royal Melbourne Hospital & ATHENS & AMPELOKIPOI \\
\hline J. Claude Hemphill III, MD,MAS & University of California, San Francisco & Parkville & Victoria \\
\hline sami fahoum & Sundsvall county hospital & San Francisco & California \\
\hline Florent GOBERT & Lyon University hospital & sundsvall & medelpad \\
\hline Alex Flaxman & Union Hospital of Cecil County & Lyon & Auvergne Rhone Alpes \\
\hline Bosque, M. Dolores & Head of Intensive Care Department & $\begin{array}{l}\text { Swedesboro } \\
\text { Sant Cugat del }\end{array}$ & NJ \\
\hline Mostafa Nabawy Ali & Nakuru hospital & Vallés & Barcelona \\
\hline Pradipta Bhakta & Cork University Hospital, Cork, Ireland. & Nakuru & Nakuru \\
\hline Haitham Osman & Mouwasat Hospitsal & Drogheda & Louth (Lú) \\
\hline René Schmutz & St. John of God Hospital & Riyadh & Central region \\
\hline Iwan van der Horst & Maastricht UMC+ & Vienna & Vienna \\
\hline Lenka Horakova & Masaryk Hospital & Maastricht & Limburg \\
\hline Maarten Vollebergh & Umcg & Usti nad Labem & Ustecky kraj \\
\hline Pedro Cavaleiro & Centro Hospitalar do Algarve & Groningen & Groningen \\
\hline Lauwers & H.Hart & Faro & Algarve \\
\hline Jean Aldo Rodríguez Díaz & ??? & Lier & Antwerp \\
\hline C Barrera Groba & BSUH & Las Tunas & Las Tunas \\
\hline Anna Hall & Zorgsaam & Brighton & Sussex \\
\hline Ilko Maier & University Medicine Göttingen & Terneuzen & Zeeland \\
\hline DIEGO MOROCHO TUTILLO & HOSPITAL DE ESPECIALIDADES EUGENIO ESPEJO & Göttingen & Niedersachsen \\
\hline Nicolas Gaspard & ULB - Hôpital Erasme & QUITO & PICHINCHA \\
\hline Alexandra Saraguro & Physician & Brussels & Brussels \\
\hline Silvia De Rosa & Sna Bortolo Hospital & Latacunga & Cotopaxi \\
\hline Gennady & Bregman & Vicenza & Italy \\
\hline Ana de Pablo & Hospital Universitario del Sureste & Rehovot & Central \\
\hline Stammet & CGDIS & Arganda del Rey & Madrid \\
\hline Celeste Dias & $\mathrm{NCCU}$ & Luxembourg & Luxembourg \\
\hline Ahmed Msherghi & University of Tripoli/Faculty of Medicine & Porto & Porto \\
\hline Laura Borgstedt & Klinikum rechts der Isar TU Munich & Tripoli & Alzawyah street \\
\hline Marcel Aries & MUMC & Munich & Bavaria \\
\hline Jeremy Henning & $\mathrm{JCUH}$ & Maastricht & Limburg \\
\hline Rob Wilting & Intensive Care ETZ & Middlesbrough & Cleveland \\
\hline Dr Vera Gotz & UHMBT & Tilburg & Brabant \\
\hline Dr Sanjay Wijayatilake & BHR NHS Trust & Lancaster & Lancashire \\
\hline Tommaso Pettenuzzo & "Santa Maria della Misericordia" Hospital & London & London \\
\hline QUINTARD Hervé & CHU Nice & Rovigo & Veneto \\
\hline Fabio S TACCONE & Hôpital Erasme & Nice & Provence-Alpes-Cote d'Azur \\
\hline Dana Rodica Tomescu & Fundeni Clinical Institute & Brussels & NA \\
\hline Kuzmin Alexey & No & Bucharest & Bucharest \\
\hline Dr Sundaresan Maiyalagan & Clinic Muller & Saint-Peterburg & Saint-Peterburg \\
\hline Siddharth Chavali & Aditya Birla Memorial Hospital & Curepipe & Curepipe \\
\hline Igor Milet & CHTMAD & Pune & Maharashtra \\
\hline Luis Antonio Gorordo-Delsol & Adult Intensive Care Unit - Hospital Juárez de México & Vila Real & Vila Real \\
\hline David Menon & University of Cambridge & México City & México City \\
\hline Philip Bastone & Oxford university hospitals NHS foundation trust & Cambridge & Cambs \\
\hline Nerina Harley & Royal Melbourne Hospital & Oxford & Oxfordshire \\
\hline Martha susana Perez & Dr & Melbourne & VIC \\
\hline Hazem Ahmed & Abo Slem Trauma Hospital & Hermosillo & Sonora \\
\hline Ian Seppelt & Department of Intensive Care Medicine, Nepean Hospital & Tripoli & Tripoli \\
\hline Jean Paul Vazquez Mathieu & Critical Care & Penrith & NSW \\
\hline Kirsten Møller & Rigshospitalet, Neurointensive Care Unit & México & D.F. \\
\hline LUIZ HENRIQUE COSTA GARCIA & UNITED HEALTH & Copenhagen & None \\
\hline
\end{tabular}


Cobilinschi

Skarzynski

Andrew Cheng

Enrique Fernández Mondejar

Eva Provaznikova

Jorge H. Mejía-Mantilla

Mohammad AshrafDrabu

seda guzeldag

Aarti Sarwal

Robert C Tasker

Guillermo Nunez

Juan Antonio Llompart-Pou

Veronika Reinhard

Edoardo Picetti

Niraj Tyagi

Andrea Marudi

ghaleb almekhlafi

Andrea Marudi

Zunairah Rais

Raul Neto

Muhammed Elhadi

Alberto Goffi

MADUABUCHI PAUL

UFOEGBUNAM

Marco Carbonara

Mathieu van der Jagt

Adrian Wong

Dr. Helmut F. Novak

Pierre Bouzat

Malin Rundgren

Carmen Lopez Soto

sahil doshi

Jan Neiser

Shazia Nasim Akhtar

Akshay hm

maria isabel gonzalez

Ditte Strange

Eduarda Pereira

Camilla Brorsson

PAYEN Jean Francois

Rainer Dziewas

JOSE MANUEL JIMENEZ

MORAGAS

$Y P$ Singh

ANA BERRAZUETA

Stine Estrup

DR PAYEL BOSE

Luis Camputaro

Jamil Dibu

Shihan mahmud Redwanul Huq
Clinical emergency hospital Bucharest

Intensivist

St George Hospital and Clinical School UNSW

ICU hospital virgen de las nieves

Physicia

Fundación Valle del Lili

Saudi council for heath specialities

medical doctor

Wake Forest Baptist Health Center

Boston Children's Hospital

Medical Director

Hospital Universitari Son Espases

Tartu University Hospital

I UO Anestesia Rianimazione

Consultant Intensivist

AOU Modena

PSMMC ICS 11159

\section{Aou Modena}

Liaquat National Hospital

Serviço de Medicina Intensiva Polivalente Centro Hospitalar Vila Nova de Gaia/Espinho

Faculty of Medicine, University of Tripoli

Interdepartmental Division of Critical Care Medicine, University of

Toronto

MEMFYS HOSPITAL FOR NEUROSURGERY

Policlinico Milano

Erasmus MC - University Medical Center

King's College Hospital

NeurolntensiveCareUnit, Christian Doppler Klinik, Paracelsus Medical University

Grenoble Alpes University Hospital

Neurosurgical intensive care Unit, Skane University Hospital

King's College Hospital

sterling hospital

University Hospital

Pakistan institute of medical sciences

Jss University

Doctor

Physician

Centro Hospitalar Universitário São João

$\mathrm{MD}, \mathrm{PhD}$

Department of Anesthesia and Critical Care, Grenoble University Hospital

Department of Neurology, University Hospital Münster

INTENSIVE CARE MEDICINE

Max Super Specialty Hospital, PPG

Dr.

Zealand University Hospital

MBBS,MD,FNB,EDIC,IDCCM,IFCCM

Hospital Juan A Fernandez

Cleveland Clinic Abu Dhabi

Associate consultant-ICU,SQUARE HOSPITAL'S LTD
MOGI DAS

CRUZES

SAO PAULO

Bukarest Bukarest

Orleans Centre

Sydney NSW

Granada Granada

Usti nad Labem Czech Republic

Cali

Riyadh

Valle del Cauca

kayseri

Riyadh region

Winston Salem NC

Boston MA

Santiago Region Metropolitana

Palma Illes Balears

Tartu Tartu

Parma Parma

Delhi Delhi

Modena $\quad \mathrm{MO}$

riyadh riyadh

Modena MO

Karachi Sindh

$\begin{array}{ll}\text { Vila Nova de } & \\ \text { Gaia } & \text { Porto }\end{array}$

Tripoli

Choose State/Province

Toronto

Ontario

ENUGU

Enugu

Fondazione

IRCCS Ca'

Granda

Ospedale

Maggiore

Policlinico

Rotterdam

Mi

London

Zuid-Holland

London

5020 Salzburg

Grenoble

Lund

Skane

London

ahmedabad gujarat

Greater London

Ostrava

MSK

Islamabad

Pakistan

Mysore

Karnataka

leon

leon

Copenhagen

Copenhagen

PORTO

PORTO

Umeå

Umeå

GRENOBLE

Münster

North Rhine Westfalia

CADIZ

CADIZ

Delhi

Delhi

SANTANDER

CANTABRIA

Roskilde

Zealand

KOLKATA

WEST BENGAL

Buenos Aires

Buenos Aires

Abu Dhabi

Abu Dhabi 


\begin{tabular}{|c|c|c|c|}
\hline Ranadhir Mitra & Care hospital & Dhaka & Dhaka \\
\hline Ali Necati Gökmen & Dokuz Eylül University Faculty Of Medicine & Bhubaneswar & Odisha \\
\hline Haifa Mesfer Algethamy & King Abdulaziz university hospital & İzmir & Balcova \\
\hline Ranadhir Mitra & Care hospital & Jeddah & Western \\
\hline Patrick Biston & CHU Charleroi & Bhubaneswar & Odisha \\
\hline George Mixides & Private Hospital ICU & Charleroi & Hainaut \\
\hline İsmail Yıldız & . & Nicosia & Nicosia \\
\hline ERIKS SLIDERS & Consultant ICM & İstanbul & Turkiye \\
\hline Aaron Blandino Ortiz & Critical Care Physician / Intensivist & $A B U D H A B I$ & ABU DHABI \\
\hline Stepani Bendel & Kuopio University Hospital & Madrid & Madrid \\
\hline Hitoshi Kobata & Osaka Mishima Emergency Critical Care Center & Kuopio & Pohjois-Savo \\
\hline mark van den boogaard & $\begin{array}{l}\text { radboudumc dep intensive care } \\
\text { Dept. of Neuroanaesthesiology, NA } 2091 \text { Rigshospitalet, University of }\end{array}$ & Takatsuki & Osaka \\
\hline Tejs Jansen & Copenhagen & nijmegen & gelderland \\
\hline $\begin{array}{l}\text { Ornella Piazza } \\
\text { Hesham Kamal Habeeb }\end{array}$ & University of Salerno & Copenhagen & Captital Region \\
\hline Keryakos & Lecturer of Internal Medicine - Minia Faculty of Medicine & Cava de Tirreni & SA \\
\hline Denis Pizhin & Centro Hospitalar Universitário de Lisboa Central, UCINC & El-Minya & El-Minya \\
\hline Sara Gamelas & Anestesiology & Lisbon & Pirtugal \\
\hline Tomasz Torlinski & University Hospitals Birmingham NHS FT & Aveiro & Aveiro \\
\hline heming nicholas & general intensive care & Birmingham & West Midlands \\
\hline Ari Ercole & Cambridge University Hospitals NHS Trust (NCCU) & garches & ile de france \\
\hline Dr Janardan Nimbolkar & Breach Candy Hospital Trust & Cambridge & Cambridgeshire \\
\hline Simon & $\begin{array}{l}\text { Vivalia } \\
\text { Department of Anesthesiology and Intensive Care Medicine, Centre }\end{array}$ & Mumbai & Maharashtra \\
\hline $\mathrm{BESCH}$ & Hospitalier Universitaire de Besancon & Arlon & Luxembourg \\
\hline Orville Baez Pravia & ICU Consultant & Besançon & NA \\
\hline Jain Nikhilesh & ESICM ISCCM & Madrid & Madrid \\
\hline $\begin{array}{l}\text { Tihamer Molnar MD PhD } \\
\text { Mauricio Alejandro Aliaga }\end{array}$ & Dept. of Anesthesiology and Intensive Care & Indore & Madhya Pradesh \\
\hline Caero & Bolivia & Pécs & Baranya \\
\hline Nino Stocchetti & Milan University & Santa Cruz & Andres Ibañez - Santa Cruz \\
\hline Walter M. van den Bergh & UMCG & Milano & MI, Italy \\
\hline Christos Efseviou & Nicosia General Hospital & Groningen & Groningen \\
\hline Fabio Micheli & Ospedale Papa Giovanni XXIII & Nicosia & Nicosia \\
\hline Natasa Sojcic & $\begin{array}{l}\text { University hospital Dubrava, Anesthesia and intensive medicine } \\
\text { Clinica delle Malattie dell'apparato Cardiovascolare IRCCS Ospedale }\end{array}$ & Seriate & Bergamo \\
\hline Matteo Sarocchi & San Martino & Genova & Italy \\
\hline
\end{tabular}


Table 1. Arterial blood pressure (ABP) Management (reported as absolute values, $\%$ on total answers and $\%$ on answers with perceived values)

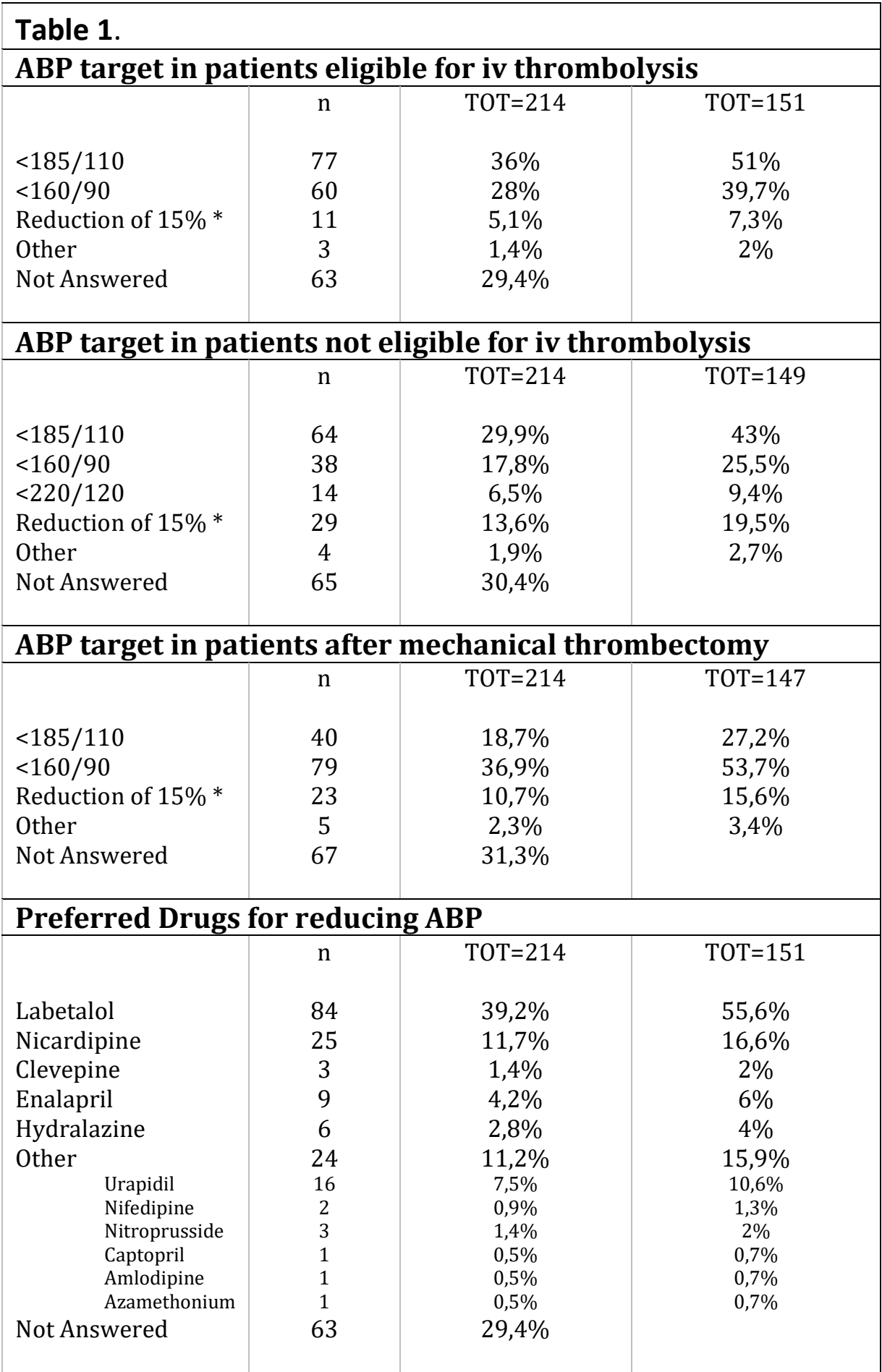

$*$ of the initial arterial blood pressure 